\title{
BACTERIOLOGICAL PROFILE AND SUSCEPTIBILITY PATTERN OF ISOLATES FROM BLOOD STREAM INFECTION AMONG IMMUNOSUPPRESSED PATIENTS IN A TERTIARY CARE CANCER CENTRE IN SOUTH INDIA WITH SPECIAL REFERENCE TO EMERGENCE OF COLISTIN AND VANCOMYCIN RESISTANCE
}

\author{
Sagila Savithri Gangadharan', Swapna Raveendra Nath², Geetha Narayanan³, Kusumakumary P4 \\ ${ }^{1}$ Assistant Professor, Department of Microbiology, Regional Cancer Centre, Thiruvananthapuram. \\ ${ }^{2}$ Associate Professor, Department of Microbiology, Regional Cancer Centre, Thiruvananthapuram. \\ 3 Professor and HOD, Department of Medical Oncology, Regional Cancer Centre, Thiruvananthapuram. \\ 4 Professor and HOD, Department of Paediatric Oncology, Regional Cancer Centre, Thiruvananthapuram.
}

\begin{abstract}
\section{BACKGROUND}

Blood stream infections (BSI) range from self-limiting infections to life-threatening sepsis causing significant mortality and morbidity. Cancer patients are generally immunosuppressed because of the disease, bone marrow transplantation, neutropenia due to chemotherapy, radiation, steroids, etc, or due to associated comorbid conditions. Growing resistance of Gram-negative bacteria to carbapenems with emerging Colistin resistance and the resistance of Gram-positive cocci to glycopeptides prompted us to conduct a study to know about the prevalent pathogens causing BSI and their susceptibility pattern which might help in the rational and empirical use of antibiotics.
\end{abstract}

\section{MATERIALS AND METHODS}

A retrospective study was conducted at a cancer care centre in South India to analyse the bacterial isolates from the patients with blood stream infections admitted to the centre and to determine the susceptibility patterns of the commonly cultured organisms over a 2-year period, July 2012 to Jun 2014.

\begin{abstract}
RESULTS
During the 2-year period, a total of 5818 blood cultures were done out of which $499(8.6 \%)$ cultures yielded growth. Of this, 483 (96.79\%) cultures yielded monomicrobial growth and $16(3.2 \%)$ cultures yielded polymicrobial growth. Of positive blood cultures, Gram-negative bacilli constituted $82.24 \%$, Gram-positive cocci $16.37 \%$ and fungi $1.40 \%$. The most frequently identified species were Klebsiella pneumoniae (28\%), Escherichia coli (20\%) followed by Pseudomonas aeruginosa (11.02\%) and Acinetobacter species $(10.02 \%)$. Of the Gram positives, Staphylococcus aureus accounted for $7.21 \%$ of isolates followed by coagulase negative Staphylococci (3.4\%) and Enterococci (2\%). Resistance to Colistin was seen in 2 strains (0.8\%) of Enterobacteriaceae. Vancomycin resistance was seen in 5 strains (33.3\%) of Enterococci.
\end{abstract}

\section{CONCLUSION}

Infections with multidrug resistant strains are on the rise. Hospitals and other acute care facilities should adopt aggressive infection control strategies to battle these pathogens.

\section{KEYWORDS}

Blood Stream Infection, Immunocompromised Patients, Antimicrobial Susceptibility, Colistin Resistance, Vancomycin Resistance.

HOW TO CITE THIS ARTICLE: Gangadharan SS, Nath SR, Narayanan G, et al. Bacteriological profile and susceptibility pattern of isolates from blood stream infection among immunosuppressed patients in a tertiary care cancer centre in South India with special reference to emergence of Colistin and vancomycin resistance. J. Evolution Med. Dent. Sci. 2017;6(13):1005-1009, DOI: $10.14260 /$ Jemds/2017/215

\section{BACKGROUND}

Cancer patients are generally immunosuppressed because of the disease, bone marrow transplantation, neutropenia due to chemotherapy, radiation, steroids, etc, or due to associated comorbid conditions. In spite of considerable advances in antimicrobial treatment, infection still continues to pose the greatest danger to these immunosuppressed patients. An

Financial or Other, Competing Interest: None.

Submission 05-01-2017, Peer Review 28-01-2017,

Acceptance 04-02-2017, Published 13-02-2017.

Corresponding Author:

Dr. Sagila Savithri Gangadharan,

Assistant Professor,

Department of Microbiology,

Regional Cancer Centre,

Thiruvananthapuram-695011.

E-mail: sajansagila@gmail.com

DOI: $10.14260 /$ jemds $/ 2017 / 215$ early and accurate aetiological diagnosis is not always easy, especially since the disease may start with minimal or nonspecific symptoms. Delayed treatment until clinical recognition of signs and symptoms of sepsis entails risk of preventable mortality. Periodic evaluation of organisms responsible for septicaemia is essential for the appropriate management of immunosuppressed patients. The growing resistance among Gram-negative bacteria to commonly used antibiotics has led to the resurgence of previously discarded antibiotics like Colistin, a neurotoxic and nephrotoxic agent, as a last-resort treatment option. A major concern is that selective pressure due to extensive Colistin use may also lead to the emergence of resistance. The emergence and spread of Vancomycin-resistant Enterococcus (VRE) in health care settings also has added risks and complexities in patient management. Most Enterococcal blood stream infections are caused by two species, E. faecalis or E. faecium. The 
emergence of VRE as an important nosocomial pathogen is due to its propensity for colonisation of the gastrointestinal (GI) tract and persistence in hospital environment. Therefore, this study was undertaken to determine the profile and antibiotic sensitivity patterns of aerobic bacteria isolated from blood cultures of cancer patients on chemotherapy and radiotherapy in a tertiary cancer care centre in Kerala.

\section{MATERIALS AND METHODS}

We conducted a retrospective analysis of laboratory records between July 2012 and June 2014 of blood cultures received in the Division of Microbiology in a tertiary care cancer centre in South India. Approval for the study was obtained from The Institutional Review Board and consent was waived since this was a retrospective evaluation (IRB No: 12/2015/04). The blood culture results analysed were received from divisions of Paediatric Oncology, Medical Oncology, Surgical Oncology and Radiation Oncology with the clinical suspicion of sepsis. The protocol for blood culture in our lab is as follows:

Two consecutive blood culture samples either from two peripheral veins or from a central line and peripheral vein (in patients having a central venous catheter) is collected under strict aseptic precautions into two automated blood culture bottles BacT/ALERT FA Plus (adults) or BacT/ALERT PF Plus (paediatric) bottles and incubated in BacT/ALERT 3D (BioMerieux) for 5 days unless specified. Gram stain and subcultures is done on blood agar and MacConkey agar when the bottle flags positive. Preliminary identification and sensitivity is done by Kirby Bauer disc diffusion testing on Mueller Hinton Agar according to the Gram stain. For Grampositive cocci, Mueller Hinton Agar supplemented with blood is used. Identification of isolates is done by conventional biochemical methods according to standard microbiological techniques. The control strains used are Staphylococcus aureus ATCC 25923, E.coli ATCC 25922 and Pseudomonas aeruginosa ATCC 27853. All the culture media is procured from HiMedia.

The drugs for disc diffusion testing are in the following concentrations: for Gram negative bacilli - Ampicillin (10 $\mu \mathrm{g})$, Cefoxitin $(30 \mu \mathrm{g})$, Cefazolin $(30 \mu \mathrm{g})$, Cefuroxime $(30 \mu \mathrm{g})$, Cefotaxime $(30 \mu \mathrm{g})$, Cefepime $(50 \mu \mathrm{g})$, Ceftazidime $(30 \mu \mathrm{g})$, Ciprofloxacin $(5 \mu \mathrm{g})$, Levofloxacin $(5 \mu \mathrm{g})$, Gentamicin $(10 \mu \mathrm{g})$, Amikacin (30 $\mu \mathrm{g})$, Doxycycline $(30 \mu \mathrm{g})$, Co-trimoxazole $(1.25 \mu \mathrm{g} / 23.75 \mu \mathrm{g})$, Amoxiclav $(20 / 10 \mu \mathrm{g})$, Cefoperazonesulbactam $(75 / 30 \mu \mathrm{g})$, Piperacillin/tazobactam $(100 / 10 \mu \mathrm{g})$, Imipenem $(10 \mu \mathrm{g})$, Meropenem $(10 \mu \mathrm{g})$, Ertapenem $(10 \mu \mathrm{g})$, Tigecycline $(15 \mu \mathrm{g})$, Colistin $(10 \mu \mathrm{g})$.

ESBL strains are confirmed by a $5 \mathrm{~mm}$ increase in zone diameter between Cefotaxime $(30 \mu \mathrm{g})$ and CefotaximeClavulanic acid $(30 \mu \mathrm{g} / 10 \mu \mathrm{g})$ or between Ceftazidime $(30 \mu \mathrm{g})$ and Ceftazidime-Clavulanic acid $(30 \mu \mathrm{g} / 10 \mu \mathrm{g})$ along with a Cefoxitin zone diameter of $>=18 \mathrm{~mm}$. Strains are considered to be resistant to $\beta$ lactam- $\beta$ lactamase inhibitor combination if Cefoxitin is resistant due to presumed AmpC production. MIC of strains suspected to produce carbapenemases and strains resistant to Colistin is determined by VITEK2. Identification of all non-fermenters is done by VITEK2.

For Gram positive cocci- Penicillin (10 units), Cefazolin (30 $\mu \mathrm{g})$, Erythromycin (15 $\mu \mathrm{g})$, Azithromycin (15 $\mu \mathrm{g})$, Cotrimoxazole $(1.25 \mu \mathrm{g} / 23.75 \mu \mathrm{g})$, Ciprofloxacin (5 $\mu \mathrm{g})$, Levofloxacin $(5 \mu \mathrm{g})$, Gentamicin $(10 \mu \mathrm{g})$, Amikacin $(30 \mu \mathrm{g})$, Doxycycline (30 $\mu \mathrm{g})$, Amoxiclav $(20 / 10 \mu \mathrm{g})$, Vancomycin (30 $\mu \mathrm{g})$ and Linezolid (30 $\mu \mathrm{g})$.Cefoxitin $(30 \mu \mathrm{g})$ was used to detect MRSA. For all vancomycin resistant Enterococci (VRE), MIC was determined by VITEK2 and confirmed.

For all isolates of Candida- Identification and sensitivity for MIC determination is done by VITEK 2 .

Data was entered in Whonet software and computed.

\section{RESULTS}

During the study period, a total of 5818 blood cultures were carried out in division of Microbiology. Blood cultures were positive in $499(8.6 \%)$ cases. Of this, $483(96.79 \%)$ cultures yielded monomicrobial growth and 16 (3.2\%) cultures yielded polymicrobial growth. Among the culture positive cases, there were 278 (55.71\%) males and 221 (44.28\%) females with the male-to-female ratio of 1.3: 1. Majority of positive samples were from febrile neutropenic patients (433 patients). Others were Blood Stream Infections associated with surgery and radiation. Gram-negative organisms caused $82.24 \%$ of the Blood Stream Infections, Gram-positive organisms caused $16.37 \%$, and fungi caused $1.40 \%$. Polymicrobial infection was documented in $3.33 \%$ (16 patients) cases. Klebsiella pneumoniae (28\%) was the most common organism causing sepsis in this institution followed by E.coli (20\%). Among the Gram positives, Staphylococcus aureus (7\%) was the predominant organism followed by coagulase negative Staphylococci (3\%) and then Enterococci (2\%). Enterococcus faecium $60 \%$ (9 strains) accounted for the majority of Enterococcal strains followed by Enterococcus faecalis $40 \%$ (6 strains). Of the Candida species (7 strains), Candida tropicalis accounted for 57\% (4 strains) of the isolates. Other organisms included Proteus mirabilis, Aeromonas species, Haemophilus influenzae, Bacillus species (Not B. anthracis), Citrobacter species, Morganella morganii and Serratia marcescens. The detailed list of the aetiological agents is shown in table 1.

Table 2 and table 3 shows the sensitivity profile of Gram negative and Gram-positive organisms respectively. Significant resistance was observed for cephalosporins, fluoroquinolones, aminoglycosides and $\beta$ lactam- $\beta$ lactamase inhibitor combinations in Enterobacteriaceae. ESBL production was noticed in $43 \%$ of E.coli and $54 \%$ of Klebsiella pneumoniae. Carbapenem resistance was noticed in 62 strains of Klebsiella pneumoniae, 16 strains of E. coli and four strains of Enterobacter species mostly to a single carbapenem. But 45 strains of Klebsiella pneumoniae, 16 strains of E. coli and two strains of Enterobacter species were found to be resistant to the three carbapenems tested. None of the antibiotics tested was $100 \%$ active against Enterobacteriaceae. Resistance to Colistin was also seen. Only 99.2\% Enterobacteriaceae isolates were sensitive to Colistin. Two strains $(0.8 \%)$ proved to be Colistin resistant which was confirmed by VITEK2.

Majority of the Acinetobacter species isolated were found to be sensitive to Doxycycline (86\%) and Levofloxacin (72\%). Significant resistance was observed for carbapenems in Acinetobacter species also (34\% to Imipenem and 30\% to Meropenem). Most of the Pseudomonas aeruginosa isolates were sensitive to the antipseudomonal antibiotics tested. Colistin resistance was not noted in Pseudomonas aeruginosa and Acinetobacter species.

Methicillin resistance was noted in nine strains of Staphylococcus aureus (25\%) and in 12 strains of coagulase 
negative Staphylococci (76.5\%). Vancomycin resistance was not seen in Staphylococci but was seen in five isolates of Enterococci (33.3\%) which were speciated as Enterococcus faecium by VITEK 2. All Gram-positive isolates were 100\% sensitive to Linezolid.

Table 4 and table 5 documents the MICs of five strains of Vancomycin resistant Enterococcus faecium and two strains of Colistin resistant Klebsiella pneumoniae respectively.

Among the 5 patients who developed VRE septicaemia, 3 patients $(60 \%)$ died in the hospital and 2 patients (40\%) survived. The mortality associated with Colistin resistant Enterobacteriaceae was $100 \%$.

\begin{tabular}{|c|c|c|}
\hline Organism & No. of Organisms & $\%$ \\
\hline Klebsiella pneumoniae & 142 & 28.45 \\
\hline Escherichia Coli & 99 & 19.83 \\
\hline Pseudomonas Aeruginosa & 55 & 11.02 \\
\hline Acinetobacter spp. & 50 & 10.02 \\
\hline Staphylococcus Aureus & 36 & 7.21 \\
\hline Enterobacter spp. & 18 & 3.60 \\
\hline $\begin{array}{c}\text { Staphylococcus, } \\
\text { Coagulase Negative }\end{array}$ & 17 & 3.40 \\
\hline Non Fermenters & 16 & 3.40 \\
\hline Enterococcus spp. & 15 & 3.00 \\
\hline Streptococci & 11 & 2.20 \\
\hline Burkholderia cepacia & 8 & 1.60 \\
\hline Candida spp. & 7 & 1.40 \\
\hline Salmonella spp. & 4 & 0.80 \\
\hline Streptococcus Pneumoniae & 3 & 0.60 \\
\hline Others & 18 & 3.60 \\
\hline
\end{tabular}

\begin{tabular}{|c|c|c|c|}
\hline \multirow{2}{*}{ Antibiotic } & \multicolumn{3}{|c|}{ Sensitivity profile in percentage } \\
\cline { 2 - 4 } & $\begin{array}{c}\text { Entero- } \\
\text { bacteriaceae } \\
\text { (270 Strains) } \\
\text { No: Sensitive } \\
\text { (\%) }\end{array}$ & $\begin{array}{c}\text { Pseudomonas } \\
\text { Aeruginosa } \\
\text { (55 strains) } \\
\text { No: Sensitive } \\
\text { (\%) }\end{array}$ & $\begin{array}{c}\text { Acinetobacter } \\
\text { spp. } \\
\text { (50 Strains) } \\
\text { No: Sensitive } \\
\text { (\%) }\end{array}$ \\
\hline Colistin & $268(99.2 \%)$ & $55(100 \%)$ & $50(100 \%)$ \\
\hline Tigecycline & $224(83.1 \%)$ & $0(0 \%)$ & $45(90 \%)$ \\
\hline Imipenem & $190(70.5 \%)$ & $50(90.9 \%)$ & $33(66 \%)$ \\
\hline Meropenem & $140(51.7 \%)$ & $47(85.5 \%)$ & $35(70 \%)$ \\
\hline Ertapenem & $157(58.2 \%)$ & NT & $25(50 \%)$ \\
\hline $\begin{array}{c}\text { Cefepime/ } \\
\text { Clavulanic acid }\end{array}$ & $113(41.9 \%)$ & $50(90.9 \%)$ & $32(64 \%)$ \\
\hline $\begin{array}{c}\text { Piperacillin/ } \\
\text { Tazobactam }\end{array}$ & $102(37.6 \%)$ & $48(87.3 \%)$ & $34(68 \%)$ \\
\hline $\begin{array}{c}\text { Cefoperazone/ } \\
\text { Sulbactam }\end{array}$ & $87(32.5 \%)$ & $44(80 \%)$ & $35(70 \%)$ \\
\hline
\end{tabular}

\begin{tabular}{|c|c|c|c|}
\hline Doxycycline & $86(31.8 \%)$ & $0(0 \%)$ & $43(86 \%)$ \\
\hline $\begin{array}{c}\text { Trimethoprim/ } \\
\text { Sulfa- } \\
\text { methoxazole }\end{array}$ & $57(21.2 \%)$ & $0(0 \%)$ & $25(50 \%)$ \\
\hline Amikacin & $153(56.7 \%)$ & $48(87.3 \%)$ & $27(54 \%)$ \\
\hline Tobramycin & $69(25.8 \%)$ & $48(87.3 \%)$ & $22(44 \%)$ \\
\hline Gentamicin & $62(23 \%)$ & $47(85.5 \%)$ & $14(28 \%)$ \\
\hline Ciprofloxacin & $52(19.2 \%)$ & $45(81.8 \%)$ & $28(56 \%)$ \\
\hline Levofloxacin & $52(19.2 \%)$ & $45(81.8 \%)$ & $36(72 \%)$ \\
\hline Cefepime & $67(24.9 \%)$ & $49(89.1 \%)$ & $19(38 \%)$ \\
\hline Cefotaxime & $42(15.7 \%)$ & $0(0 \%)$ & $4(8 \%)$ \\
\hline Ceftazidime & $41(15.3 \%)$ & $46(83.6 \%)$ & $9(18 \%)$ \\
\hline Aztreonam & $38(14.3 \%)$ & $49(89.1 \%)$ & $16(32 \%)$ \\
\hline Cefuroxime & $40(14.7 \%)$ & $0(0 \%)$ & $4(8 \%)$ \\
\hline Cefazolin & $28(10.5 \%)$ & $0(0 \%)$ & $0(0 \%)$ \\
\hline \multicolumn{4}{|c|}{ Table 2. Sensitivity Profile of Gram-negative Isolates } \\
\hline
\end{tabular}

NT- Not Tested

\begin{tabular}{|c|c|c|c|}
\hline \multirow[b]{2}{*}{$\begin{array}{c}\text { Antibiotic } \\
\text { Name }\end{array}$} & \multicolumn{3}{|c|}{ Sensitivity Profile in Percentage } \\
\hline & \begin{tabular}{|} 
Staphylococcus \\
Aureus \\
(36 Strains) \\
No: Sensitive \\
(\%)
\end{tabular} & $\begin{array}{c}\text { Coagulase } \\
\text { negative } \\
\text { Staphylococci } \\
\text { (17 Strains) } \\
\text { No: Sensitive } \\
\text { (\%) }\end{array}$ & $\begin{array}{c}\text { Enterococci } \\
\text { (15 Strains) } \\
\text { No: Sensitive } \\
(\%)\end{array}$ \\
\hline Vancomycin & $36(100 \%)$ & $17(100 \%)$ & $10(66.7 \%)$ \\
\hline Linezolid & $36(100 \%)$ & $17(100 \%)$ & $15(100 \%)$ \\
\hline Doxycycline & $36(100 \%)$ & $14(83.3 \%)$ & $3(20 \%)$ \\
\hline Penicillin G & $3(8.3 \%)$ & $3(17.6 \%)$ & $1(6.7 \%)$ \\
\hline Ampicillin & NT & NT & $3(20 \%)$ \\
\hline $\begin{array}{c}\text { Amoxicillin/ } \\
\text { Clavulanic Acid }\end{array}$ & $11(31.4 \%)$ & $3(17.6 \%)$ & $0(0 \%)$ \\
\hline Cefazolin & $27(75 \%)$ & $4(23.5 \%)$ & $0(0 \%)$ \\
\hline Cefoxitin & $27(75 \%)$ & $4(23.5 \%)$ & NT \\
\hline $\begin{array}{c}\text { Gentamicin- } \\
\text { High Level }\end{array}$ & NT & NT & $5(33.3 \%)$ \\
\hline Gentamicin & $28(77.1 \%)$ & $9(52.9 \%)$ & NT \\
\hline Clindamycin & $27(75 \%)$ & $10(60 \%)$ & $0(0 \%)$ \\
\hline Azithromycin & $13(35.5 \%)$ & $3(17.6 \%)$ & $0(0 \%)$ \\
\hline Erythromycin & $16(44.4 \%)$ & $5(29.4 \%)$ & $0(0 \%)$ \\
\hline Ciprofloxacin & $11(30.3 \%)$ & $9(53.3 \%)$ & $2(13.3 \%)$ \\
\hline $\begin{array}{c}\text { Trimethoprim/ } \\
\text { Sulfa- } \\
\text { methoxazole }\end{array}$ & $26(71.9 \%)$ & $10(60 \%)$ & NT \\
\hline
\end{tabular}

NT- Not tested

\begin{tabular}{|c|c|c|c|c|c|c|}
\hline $\begin{array}{c}\text { Species } \\
\text { (No. Tested) }\end{array}$ & $\begin{array}{c}\text { Antimicrobial } \\
\text { Agent }\end{array}$ & $\begin{array}{c}\text { MIC }(\mathrm{mcg} / \mathrm{mL}) \\
1^{\text {st }} \text { Strain }\end{array}$ & $\begin{array}{l}\text { MIC }(\mathrm{mcg} / \mathrm{mL}) \\
\text { 2nd Strain }^{\text {nd }}\end{array}$ & $\begin{array}{c}\text { MIC }(\mathrm{mcg} / \mathrm{mL}) \\
\text { 3rd Strain }\end{array}$ & $\begin{array}{c}\text { MIC }(\mathrm{mcg} / \mathrm{mL}) \\
4^{\text {th }} \text { Strain }\end{array}$ & $\begin{array}{c}\text { MIC }(\mathrm{mcg} / \mathrm{mL}) \\
5^{\text {th }} \text { Strain }\end{array}$ \\
\hline \multirow[b]{2}{*}{ Enterococcus } & Ampicillin & $\geq 32$ & $\geq 32$ & $\geq 32$ & $\geq 32$ & $\geq 32$ \\
\hline & Vancomycin & $\geq 32$ & $\geq 32$ & $\geq 32$ & $\geq 32$ & $\geq 32$ \\
\hline \multirow{4}{*}{ Faecium (5) } & Quinupristin- Dalfopristin & 1 & 1 & 1 & 0.5 & 0.5 \\
\hline & Linezolid & 1 & 1 & 1 & 2 & 2 \\
\hline & Tetracycline & $\geq 16$ & $\geq 16$ & $\geq 16$ & $\geq 16$ & $\geq 16$ \\
\hline & Tigecycline & $\leq 0.12$ & $\leq 0.12$ & $\leq 0.12$ & $\leq 0.12$ & $\leq 0.12$ \\
\hline
\end{tabular}

Table 4. MIC Pattern of Vancomycin Resistant Enterococci (VRE) 


\begin{tabular}{|c|c|c|c|}
\hline $\begin{array}{l}\text { Species } \\
\text { (No. } \\
\text { Tested) }\end{array}$ & $\begin{array}{c}\text { Antimicrobial } \\
\text { Agent }\end{array}$ & $\begin{array}{c}\text { MIC } \\
(\mathrm{mcg} / \mathrm{mL}) \\
1^{\text {st }} \text { strain }\end{array}$ & $\begin{array}{c}\text { MIC } \\
\text { (mcg/mL) } \\
2^{\text {nd }} \text { strain }\end{array}$ \\
\hline \multirow{12}{*}{$\begin{array}{c}\text { Colistin } \\
\text { Resistant } \\
\text { Entero- } \\
\text { Bacteriaceae } \\
\text { (2) }\end{array}$} & Ampicillin & $\geq 32$ & $\geq 32$ \\
\hline & $\begin{array}{l}\text { Amoxicillin- } \\
\text { Clavulanic Acid }\end{array}$ & $\geq 32$ & $\geq 32$ \\
\hline & Cefepime & $\geq 32$ & $\geq 32$ \\
\hline & $\begin{array}{l}\text { Piperacillin- } \\
\text { Tazobactam }\end{array}$ & $\geq 128$ & $\geq 128$ \\
\hline & $\begin{array}{l}\text { Cefoperazone- } \\
\text { Sulbactam }\end{array}$ & $\geq 64$ & $\geq 64$ \\
\hline & $\begin{array}{c}\text { Trimethoprim/ } \\
\text { Sulfamethoxazole }\end{array}$ & $\geq 320$ & $\geq 320$ \\
\hline & Imipenem & $\begin{array}{c}2 \\
\text { (Resistant) }\end{array}$ & $\begin{array}{c}2 \\
\text { (Resistant) }\end{array}$ \\
\hline & Meropenem & $\geq 16$ & $\geq 16$ \\
\hline & Ertapenem & $\geq 8$ & $\geq 8$ \\
\hline & Ciprofloxacin & $\geq 4$ & $\geq 4$ \\
\hline & Tigecycline & $\geq 8$ & $\begin{array}{c}4 \\
\text { (Intermediate) }\end{array}$ \\
\hline & Colistin & $\geq 16$ & $\geq 16$ \\
\hline \multicolumn{4}{|c|}{$\begin{array}{l}\text { Table 5. MIC pattern of Colistin } \\
\text { resistant Enterobacteriaceae }\end{array}$} \\
\hline
\end{tabular}

\section{DISCUSSION}

Blood stream infections remain a huge health care concern in terms of morbidity and mortality throughout the world. Patients with haematological malignancy are immunocompromised due to being on immunosuppressive therapy or steroids. The risk of infection is greatest in patients with neutropenia in whom Gram-negative bacteria cause severe sepsis associated with a high mortality rate.1,2 In this retrospective study as in other studies, it is seen that only a minor percentage of blood stream infection is microbiologically documented even in the presence of sepsis. The blood culture positivity in our study was $8.3 \%$, which was quite low compared to the rates reported earlier in other studies.2,3,4 The reason for this could be possibly due to blood culture being sent in the event of fever in the absence of sepsis. In our study, the Gram-negative isolates accounted for a higher percentage of Blood Stream Infections compared to Gram positives which is similar to many other studies. $1,5,6,7$ Candida tropicalis was the most common fungal isolate which correlates well with other studies. ${ }^{1,8}$ An increase in resistance to most of the commonly used antimicrobials has been noted in our study. Vancomycin resistance in Enterococci was seen in five patients. Of them, two patients improved with Linezolid and a combination of Linezolid and Tigecycline. Of the remaining, one patient had polymicrobial infection with multi drug resistant Acinetobacter species and VRE. Three patients succumbed in spite of treatment with Linezolid and Tigecycline.

Carbapenem-resistant Enterobacteriaceae (CRE) are emerging global pathogens. Presence of such strains in immunosuppressed patients has ominous implications. Infections caused by CRE are associated with mortality rates approaching 50\%. ${ }^{9}$ In our centre also, carbapenem resistant strains are emerging with very limited treatment options. Similar resistance profile to carbapenems was noticed in Acinetobacter species also but not in Pseudomonas aeruginosa. The reason for this is not clear. Moreover Colistin resistance in Klebsiella pneumoniae has also emerged. The most common mechanisms of resistance to Colistin in Enterobacteriaceae are modifications to lipopolysaccharide. In Klebsiella pneumoniae, capsules may also play a part. A study by Antoniadou et al has demonstrated that extensive use of Colistin leads to the development of resistance among Klebsiella pneumoniae isolates with increasing morbidity and mortality of critically ill patients. ${ }^{10}$ In our patients, both the patients were treated with a combination of carbapenem, Colistin and Tigecycline in spite of resistance. Both the patients succumbed to the infection. As Colistin is the last line of defense against these troublesome carbapenemaseproducing CRE isolates, the development of resistance to Colistin is of major concern. Hence, there is a growing requirement of novel antibiotics against Gram-negative bacilli. Also strict infection control practices, rational use of the available antibiotics and antibiotic stewardship should be put up to prevent the spread of these multidrug resistant strains.

\section{CONCLUSION}

The present study provides much needed information on the prevalence of different pathogens in blood stream infections which highlights the need for periodic surveillance of aetiologic agents, the changing trends in their susceptibility pattern to prevent further emergence and spread of resistant pathogens. Awareness regarding the resistant isolate prevalent in hospital environment followed by infection control practices is the first step that a clinical microbiologist can take to address this problem. New agents, combination therapies, and improved dosing strategies hold promise for the treatment of VRE. But literature regarding appropriate therapy for CRE infections is limited, as are the options of clinically available antimicrobials. Hospitals and other acute care facilities should adopt aggressive infection control strategies to battle these pathogens.

\section{REFERENCES}

[1] Gupta A, Sharma S, Arora A, et al. Changing trends of in vitro antimicrobial resistance patterns in blood isolates in a tertiary care hospital over a period of 4 years. Indian J Med Sci 2010;64(11):485-92.

[2] Arora U, Devi P. Bacterial profile of blood stream infections and antibiotic resistance pattern of isolates. JK Science 2007;9(4):186-90.

[3] Al FM, Blanco CS, Sanchez MF, et al. Study on bacteremia in the service of internal medicine of a group 2 hospital. Analysis of recent three years. Ann Med Interne 2005;22(5):217-21.

[4] Mehdinejad M, Khosravi AD, Morvaridi A. Study of prevalence and antimicrobial susceptibility pattern of bacteria isolated from blood cultures. J Biol Sci 2009;9(3):249-53.

[5] Marra AR, Camargo LF, Pignatari AC, et al. Nosocomial bloodstream infections in Brazilian hospitals: analysis of 2,563 cases from a prospective nationwide surveillance study. J Clin Microbiol 2011;49(5):186671.

[6] Qureshi M, Aziz F. Prevalence of microbial isolates in blood cultures and their antimicrobial susceptibility profiles. Biomedica 2011;27:136-9. 


\section{Jemds.com}

[7] Prabhash K, Medhekar A, Ghadyalpatil N. Blood stream infections in cancer patients: a single center experience of isolates and sensitivity pattern. Indian J Cancer 2010;47(2):184-8.

[8] Mathur P, Varghese P, Tak V, et al. Epidemiology of blood stream infections at a level-1 trauma care center of India. J Lab Physicians 2014;6(1):22-7.

[9] Satlin MJ, Jenkins SG, Walsh TJ. The global challenge of carbapenem-resistant Enterobacteriaceae in transplant recipients and patients with hematologic malignancies. Clin Infect Dis 2014;58(9):1274-83.

\section{Original Research Article}

[10] Antoniadou A, Kontopidou F, Poulakou G, et al. Colistin-resistant isolates of Klebsiella pneumonia emerging in intensive care unit patients: first report of a multiclonal cluster. J Antimicrob Chemother 2007;59(4):786-90. 